\title{
University Education in Algeria during the Covid-19 Pandemic: Limitations and Challenges
}

Arab World English Journal (AWEJ) Volume 12. Number3 September 2021

DOI: https://dx.doi.org/10.24093/awej/vol12no3.2

Pp. 16-35

\section{Nassima Kerras}

Department of Global Studies, Pompeu Fabra University, Spain

Correspondent Author: Nassima.kerras@upf.edu

Salah Eddine Salhi

Department of Letters and Languages, Tlemcen University, Algeria

Received: 6/22/2021 Accepted: 8/28/2021 Published: 9/24/2021

\section{Abstract}

The study deals with the subject of learning languages online. Many studies (Chelghoum \& Chelghoum, 2020; Arabeche \& Soudani, 2021) have been carried out over the last year to investigate the needs of the pedagogical changes as a result of the world health situation. The Covid-19 pandemic wreaked havoc all over the globe. This unprecedented situation created huge complications for citizens worldwide, with emergency offices suddenly appearing in students' and workers' kitchens, bedrooms, and living rooms due to the large-scale lockdowns and stringent restrictions on movement put into place by governments. The sudden and unexpected nature of this "new normal" left very little time for acclimatisation to the online learning modes, with students and teachers alike adapting and improvising. This study aims to investigate the difficulties of Algerian students and analysing the interactive techniques which could be applied in language studying, and overcoming the barriers of computer screens. In this case, we address the goals used in university teaching in Algeria to be able to understand the situation and draw a possible new strategy to achieve a quality education. First, the topic is introduced, followed by an analysis of teaching and learning methods during the COVID-19 pandemic. Afterwards, the methodology is defined, highlighting the relation between the Psycholinguistics (Hanim Rahmat, 2018) and the Communicative Approach (Hymes, 1972). A qualitative study is carried out to describe the problems faced by the students and offer some possible recommendations, taking into account the social context experienced during the 2020-2021 academic year.

Keywords: Algerian universities, challenges and limitations, communicative approach, COVID19 , education, learning languages, psycholinguistics

Cite as: Kerras, N.,\& Salhi , S. E. (2021). University Education in Algeria during the Covid-19 Pandemic: Limitations and Challenges . Arab World English Journal, 12 (3) 16-35.

DOI: https://dx.doi.org/10.24093/awej/vol12no3.2 


\section{Introduction}

Shortly after the Covid-19 pandemic broke out in Wuhan, China in December 2019, information about the virus and its potential impact began to filter across the globe through international news agencies. A feeling of anxiety and concern dominated the media, business meetings and private conversations in all corners of the world, with the realisation that globalization and freedom of movement would make the virus circulate extremely rapidly. Indeed, just a few months later, this fear became a reality with many countries finding themselves facing an uncontrollable situation. The then-unknown virus began to threaten the lives of the citizens all around the world and scientists were lacking the resources and know-how to find a quick remedy; Algeria found itself equally ill-prepared (Arabeche \& Soudani, 2021).

The first official case of COVID-19 in Algeria was confirmed in February 2020, and months later the government took the decision to accelerate a partial confinement, which created a feeling of perplexity for students who were not at all used to studying online. On $2^{\text {nd }}$ April 2020, lecture theatres and seminar rooms were abandoned on government orders, in circumstances which were described as unusual and exceptional (Makhlouf, 2020).

In normal conditions, Algerian students were unfamiliar with managing and operating online platforms and software. Faced with the Covid-19 situation, the complexity is even more accentuated with the students now faced with another obstacle: that of studying exclusively in front of a screen. This situation has been discussed by several specialists including Rapanta, Botturi, Goodyear and Guàrdia (2020) who commented: "The COVID-19 pandemic has raised significant challenges for the higher education community worldwide. A particular challenge has been the urgent and unexpected request for previously face-to-face university courses to be taught online" (p. 923).

At markedly short notice, universities were presented with the daunting task of adapting online platforms to offer classes of a sufficient standard expected for high level learning. This modality allows the continuity of teaching and learning, though a high number of students were not accustomed to these types of tools even if the universities already had an e-learning teaching platform. This tool is used to host online courses and conferences, supply course materials for teachers, notes from students of different cycles and to host all the educational and research activities that take place at the university (national and international conferences, colloquia national and international, seminars, study days, professional days, etc.) (Makhlouf, 2020).

One recurring issue is related to the user's technological skills and the facilities available; some students experienced difficulties connecting to online classes due to Internet and Wi-Fi problems, while others encountered user troubles with the platforms themselves. The majority suffered with these types of problems (Guemide \& Maouche, 2021), though an even greater quandary was a mental one. Students found themselves in the predicament of working alone attempting resolve their mental and technological concerns.

Teleworking and teletraining or distance education, in this case, in digital format has recently been essential for society to function; it has been a huge failure in Algeria since there has been a distinct lack of fluency in communication (Chelghoum \& Chelghoum, 2020), which leads us to the following research questions: 
- What are the goals and strategies used in university teaching in Algeria?

- What are the main problems which students and teachers face due to this sudden and unexpected change in the educational system?

- What conclusions can be drawn regarding the new teaching-learning method one year after the beginning of the COVID-19 pandemic?

This work consists of analysing the educational situation during the Covid-19 pandemic and examining the failure that has occurred in Algeria to offer the continuity of classes to students and thus achieve the pedagogical objectives set at the beginning of the year. This failure due to the pandemic allows for the opportunity to rethink the teaching methodology in order to reflect about offering a quality education in the short term in Algeria. The following section investigates the factors that have hindered the learning of languages during the pandemic.

\section{Literature Review}

\section{Learning Languages during the Pandemic in Algeria}

The teaching and learning of languages changed abruptly from the face-to-face mode to the online mode and several points must be taken into account to explain the difficulties encountered by the students in Algeria.

Communication in language classes at university is usually direct. The teacher is the sender of the information or the message and the students are recipients (vertical communication) or vice versa when it comes to languages or translation (horizontal communication) in which both parties are protagonists in the class. The broadcast channel is usually direct or multilateral. The modality in Algeria is usually direct and the protagonist in class is characteristically the teacher, while students have become used to being passive in class (Khelfaoui, 2021). Interaction is poor, even when the teacher endeavours to create this connection. Traditionally, vertical communication prevails and this is due to the exceedingly high number of students in each group, making vertical communication challenging, as well as having had the tradition of the teacher acting as the main transmitter of information and the student as the simple receiver for many years. It has often been remarked that this is an element that must be changed in Algerian universities, adding to that the respect that the professor has and the reluctance that the students have to debate in class. However, the pandemic influences student motivation and interest and further complicates the atmosphere in which the class takes place (Arabeche \& Soudani, 2021). This point of view is supported by Priyo, Arief and Nugroho (2020) as follows: "In online learning, it is also hard to strengthen the emotional bond between the teacher and the students. It is due to the absence of physical touch and interaction in online learning" (p. 78).

In Algeria, some universities were obliged to suspend all in-person educational activities of teaching and supervision for the benefit of students during some months (Lassassi, Lounici, Sami, Tidjani, \& Benguerna, 2020), and student enthusiasm can be severely hindered by the computer screen, which acts as a barrier and impedes fluid communication between a student and their teachers and classmates (Blizak, Blizak, Bouchenak, \& Yahiaoui, 2020). Specialists in Algeria, and indeed all over the world, must work relentlessly to overcome these complications and find new and more effective communicative methods in the world of online education. Reimers and Schleicher (2020) described it in this way: "Education leaders should adopt a 
proactive approach to contributing to the mitigation of the impact of the Pandemic and to prevent learning loss during the period of necessary social distancing" (p. 7). This is a problem encountered by students throughout the months of confinement.

For students, some form of contact and interaction with classmates and the teacher is almost essential, as expressed by Rapanta, Botturi, Goodyear, and Guàrdia (2020) "Successful online learning means not feeling alone and not forgetting that learning is social: we learn from others and with others, even if at a distance" (p. 931).

The majority of students do not master technological instruments, which is a huge, existing problem in Algeria (Abdelouafi, 2021) since most language students tend not to search for information on the Internet, but via hard copies of books and the information issued by the teacher. Independent research is generally limited and when students do search for information, it is done in a rather rudimentary way. It is crucial here to point out the distinct lack of emphasis on, or even an introduction to, digital training in language and translation classes. Research is limited to very theoretical resources, such as dictionaries and language books, when it should be the time to emphasise the importance of digital platforms. Not only can this be an obstacle for the learners, but the teachers and professors themselves can also, at times, find their inadequate expertise exposed, as manifested by Bashitialshaeaer, Alhendawi, and Lassoued (2021): "A large number of professors and students indicated the lack of remote communication capabilities (devices, internet, applications, etc.)" (p. 13).

It seems that the responsibility lies with the student to improve their technological expertise, though the teacher should also be proactive in catering to the students' needs and interests and teaching the language in a way in which the students can absorb the information in a fun, interesting and modern way.

Additionally, deductive learning can be promoted amongst those participating in group classes, who can take advantage of their classmates' errors by ensuring they pay attention when others are speaking, as well as focusing on the teachers' corrections. However, it is difficult for this learning method to be applied given the limitations of doing the classes in groups and organising workshops in Algeria (Guemide, 2020; Hadjeris, 2020).

Fortunately, group work is enabled by the use of various online platforms. Bonds can be built and existing relationships maintained by dividing the class into smaller, more private groups. Within these more intimate surroundings, students are presented with the possibility of speaking directly with their peers in order to debate, exchange ideas and even complete projects, exercises and tasks together. But these tools are rendered useless when some students are unaware of the existence of such resources or when their information is limited and no instructions have been received from the teacher or ICT specialists (Lassassi et al. 2020).

As for learning languages, a great deal of effort is required both in class and outside of it. Mastering a new language, or even acquiring a decent, conversational level, is a continuous process requiring a lot of time and dedication. Extra studying in the students' own time and reviewing material to reinforce vocabulary learning, for example, and not just revising the day prior to an exam is essential. The need for self-study leads to further potential problems; to 
enable the learner to comfortably study in their own time, all material and concepts must be clearly explained by the educator (Germán, 2003). The material is generally written in a foreign language and the student may easily and understandably become discouraged when faced with the arduous task of translating all concepts and instructions. Therefore, ensuring the student is fully informed of the tasks in hand for their study sessions is vital, and this is where the significance of effective communication becomes apparent, be it during class time or through other communicative tools such as email or instant messaging services. Algerian educators need to be aware of this and maintain ongoing interaction with their students even if it takes a long time (Lassassi et al., 2020); something which has been done in all universities all over the world during the times of the COVID-19 pandemic.

Another issue arises here, which is that the teacher often feels compelled to translate parts of the classes into other languages to prevent the students from losing track of the lesson, especially given the time restrictions when teaching online. Translation is not habitually a favourable method of teaching or learning a language (Balboni, 2017), though it is much more viable to exclusively use the target language during face-to-face classes as the teacher is able to use additional non-verbal communication to assistant the learners and clearly explain theories. Online classes, however, do not facilitate this communication and translation is often used. Without these translations, students can quickly lose interest and stop paying attention to the class due to language and understanding boundaries. It is difficult to recover from such a loss of interest, which can - in turn - have a negative impact on grades and a general level of development in the subject. For these reasons, finding or creating various communicative and interactive tools which help to capture and keep the attention of the students is vital. According to Makhlouf (2020): the teachers had access to various platforms for the transmission of information. However, most of the students were lost for months, unable to reach or understand the operation of the platforms.

Therefore, both the teacher and the student must demonstrate flexibility and a willingness to learn these tools, which is mentioned here: "In the COVID-19 emergency situation, teachers have, almost overnight, been asked to become both designers and tutors, using tools which few have fluently mastered" (Rapanta et al., 2020, p. 926).

Taking these challenges into account, the teachers have even more required tasks to fulfil their objectives. These points are discussed below.

\section{Limitations of Distance Learning in Algeria}

The responsibility of conveying information lies with the teacher, who must also grab the attention and retain the interest of the student. Purba (2018) ensures that: "Humans can be directed to do something by giving them a relaxed atmosphere with an open and peaceful mind. These will stimulate nerves to easily respond and store the information for longer" (p. 53). Successfully completing these two objectives simultaneously is by no means a straightforward task, hence information must be presented in a coherent and comprehensible yet stimulating way (Chelghoum \& Chelghoum, 2020). Of course, the collaboration of the student is absolutely vital for a positive outcome to be reached. University professors have to adapt quickly and seamlessly to the new online platforms and a set of previously-unknown technological systems. The objective is to adapt the teaching of languages to this technology for effective classroom 
communication. In Algeria, though, the preparation was not particularly fast or successful; an idea which is discussed by Zermane and Aitouche (2020):

If its content enumerates the gains, we have lost due to the current status of digitization in the country. However, at the same time, it defines the areas and workshops that must be opened soon, to try to take advantage of this crisis, and identify our digital weaknesses so that we can quickly strengthen them and advance this sector, in a way that positively affects the general situation in the country and preparing ourselves for the future. (p. 162)

Extra material, away from the course books, must be found or created by the teacher - especially involving audio and visual exercises which aid the assimilation of new information. In this day and age, students are used to receiving huge amounts of easily-accessible information without making a great effort to find it, something what can be largely attributed to the wide use of the Internet. For these reasons, programs such as PowerPoint - with descriptive images and videos with easy-to-absorb illustrations - are key to helping the student study alone at home. A variety of resources can help teachers, such as glossaries, word banks, sample or model responses, sentence starters and clear and concise directions (TNTP, 2020).

Nonetheless, depending on reliable resources in online teaching is a key ingredient, as it is an effective way to present content accurately. Suitable materials are accurate in content, accessible to students and satisfactory to their level of autonomy; moreover, they should fit within the overall learning design through appropriate framework. Some materials might be practical because they stimulate reflection; others because they require action and interaction from the learners; others because they present content clearly, etc. The same could be said for students producing materials: it can make sense and prove effective if framed within a complete course design. Some teachers recognise the failure in teaching and learning online in Algeria even with students of engineering who are used to online platforms and have the necessary skills to manage virtual classes; something which language learners may not possess:

Lecturers have moved to virtual classrooms, all thanks to tools such as Zoom, Google Hangouts, and Microsoft Teams. Nevertheless, there are some still struggling to get online. The quick turn to platforms like Zoom is disrupting curricula, particularly for professors less equipped to navigate the internet and the particularities of managing a classroom mediated by a screen and microphone. Several professors cancel classes because they had technical difficulties, trouble with $\mathrm{WiFi}$, or were simply panicked over the prospect of teaching the full class over the new platform. (Zermane \& Aitouche, 2020, p. 164)

The most effective form from our experience is the synchronous one so that direct contact with the student is maintained even if the other modalities can be combined at times. Some problems arose in Algerian universities, according to a study by (Lassassi et al., 2020): The use of equipment by teachers is insufficient for success, due to the lack of training and the inexperience of teachers in this new form of education. There is a distinct lack of technological expertise, qualified personnel and adequate equipment, very little technical assistance, scarce follow-up from the service provider, as well as equipment malfunctions at several universities and poor internet quality experienced by many users. 
These problems were encountered in several universities in the world, but the awareness and speed of finding solutions in other parts of the world meant that there was no, or little, interruption in the education field in order to achieve the pedagogical and economic objectives of the country, since without an adequate education one cannot even begin to consider a sustainable and inclusive society. As Guessar (2020) mentioned in her article, "education is the best investment and that the educated individual is the basis of progress and advancement in a changing society, developed and open to all that is new" (p. 79).

The creation of simple systems and portals is possible in all countries of the world, even in those where there is a substandard quality of internet. PDF documents and videos that compile the vocabulary studied in class is a way of informing students and aiding their learning at distance is possible in this way, including when the communication is not direct but via email. The majority of Algerian students have email access and it is a tool which can be used to uphold interaction with them, even if the teaching platforms have not been accessible for whatever reason.

For Master's students, and students carrying out their end of degree projects, one commonly-adopted approach is to use a variety of means when communicating in order to maximise speed, efficiency, and effectiveness. As the aforementioned courses and projects are carried out individually, or done in small groups, it is feasible to use the telephone to facilitate communication; one way of doing so is by holding sessions such as a question-and-answer session through instant messaging applications to offer individual feedback. According to Guessar (2020) there is little interest or awareness:

Awareness of the professor as well as his lack of interest in this type of education due to the lack of interest on the part of officials in this type of education because they are from the traditional education generation. (...) And the student's lack of desire for this type of learning because he wants ready-made lectures, and prefers the traditional method so that the latter is characterized by the lack of effort on the part of the student who is content to receive only. (p. 80)

It is not a case of looking to pick faults in the teachers and students, or debate about who has more interest than the other, but it is about having the initiative to make a change within society even when the officials do not push towards positive change. It is the responsibility of every citizen in society and it is not about waiting for what the state or the student can offer. By making this extra effort, the teacher is taking steps in the right direction. The student must find a way to follow the teacher's instructions and should the teacher push the process of change, the student follows it as there is little alternative and a small change will be noticed even when the rates are slower than they should be.

Creativity is another essential aspect on the teacher's part, as long as the students respond positively to the proposals. Preparation to achieve these goals is highly important and requires significantly more time than face-to-face classes to give as much detail as possible to students (explanations via email, visual support, psychological support, etc.), to suit a variety of contexts and differing learning styles. 
The importance of student participation is clear; for this reason, teachers must find a way to use their creativity, adapt the material, provoke dynamic exchanges, and challenge the student to participate and not lose their interest (Ellis, Skehan, Li, \& Lambert, 2019).

Basically, it is all about achieving a high-quality level of teaching and this is attained through a great deal of effort from both sides: the teacher as the person responsible for transmitting the information and the student as the recipient of it. The teacher can provide socioemotional support (Guslyakova \& Guslyakova, 2020), innovation of education, discipline, incorporation of technology, individual tutoring and small learning groups to facilitate processes in the learning of critical subjects which are fundamentally important (IESALC, 2020), and the student must co-operate - otherwise, the communication system undoubtedly fails and the overall process does not have the desired impact. Students must find a way to connect to the online classes, or at least receive the emails and act upon them accordingly. Knowing that most Algerian students have social media applications means that they also have the ability to access

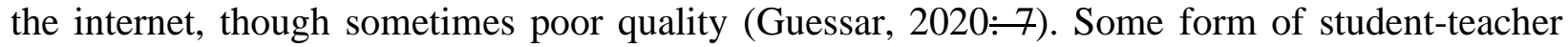
contact can be maintained, albeit indirectly, but it must be constant and taken seriously to learn and continue with the initially proposed program, even if the non-mastery of the IT tools hinders the progress somewhat (Benkhider \& Kherbachi, 2020). There are very simple platforms available which allow contact to be maintained between both parties involved in the learning process.

Many studies show that it is the student who encounters difficulties in following the classes online (Guemide \& Maouche, 2020), or lacks the necessary motivation to study online because they are used to traditional, face-to-face classes (Lassoued, Alhendawi, \& Bashitialshaaer, 2020). However, the professor is the focus in Algerian universities and perhaps it is time for the professor to make some amendments and compel the students to follow the lessons and in this way make the change from the traditional structure. The same authors mention in their article that the professors and the university administration did not work on preparing e-courses in anticipation of this unexpected crisis. But in no University, even in the most developed and technologically-advanced European countries were they prepared for the sudden switch to online classes, with large scale changes made from one day to the next. With an enormous amount of willpower and motivation, it was achieved in 24 hours and above all with the active participation of teachers, administrators, heads of departments and students with effective communication among all.

The lack of contact between the teacher and the student is a major hurdle in the attempt to succeed in distance learning in Algeria. Interaction is essential in language classes (Deli Girik Allo, 2020), and encouraging - or even pushing - students to participate is more than recommended, as Guofang (2020) comments, that promoting meaningful interaction in the classroom and engaging students in the assessment process are important. In this way, an equal and inclusive education can be provided for everybody (IESALC, 2020). The student must participate in this process to prepare or review the material that is written or orally communicated (Rapanta et al., 2020).

The most prominent flaw in this modest work is the limited introduction of technological tools in language classes in Algeria (Alla, 2021). Students still have the mentality of searching 
for information in a rudimentary way, asking questions without taking the initiative to search for information independently. A greater variety of technological tools would help to overcome this pedagogical failure in Algeria and would have been a significant help for students when attempting to acclimatise to online classes or at least to handle university platforms. On the other hand, the communication failure between students and teachers has made it even more difficult to access the information and consequently to follow the thread and not lose months of potential learning hours without any activity in various language and translation departments. The existing literature gap related to this subject in Algeria is evident, this urges the university community to take urgent measures for a qualitative leap in education with regards to emotional and communicative mechanisms that encourage students, and therefore, we can speak about quality education. This will be possible thanks to the coordination between professors and researchers without waiting for the help of the State that is currently facing difficulty.

Taking everything into consideration, the methodology to achieve a quality education in language and translation classes in Algeria is proposed in the following section.

\section{Methods}

To look deeper into the topic, a qualitative method is applied and a questionnaire is carried out, which aims to gather information to understand the situation under study, attending to reflection and analysis based on experience, with the purpose of promoting changes in language teaching in Algeria.

It is a scientific method of observation to collect data, through interviews and reflection. Qualitative research collects cases and then proceeds to their interpretation. It is based on case studies and personal experiences, which means understanding the reality in its natural and everyday context, to interpret phenomena according to the meanings given to it by the people involved - in this case, regarding the study of languages.

Various specialists studied theoretical approaches to language learning and acquisition and contributed significantly to the study of language as a scientific discipline. Amongst some of the noteworthy studies, there is the Communicative Approach (Skinner, 1957; Halliday, 1975). Communicative and interactive tools help to capture the attention of the students for an effective class based on interaction and intercommunication (Saeed \& Congman, 2013). This methodology has been absent during the pandemic in Algerian universities because, in most cases, the professor merely uploaded notes and posted material on the designated online platforms; direct communication was awfully limited. Besides this, it is important to introduce psycholinguistics mechanisms that are considered essential to create a connection with students and attract their attention (Cherrey, 2016; Toussaint, 1967).

The following section presents the results of the survey responded to by Algerian students in order to find out their needs and opinions regarding distance learning and online courses.

\section{Instruments}

A mixed questionnaire was created online through the Drive platform to determine the difficulties of the students. It was aimed at Algerian students of foreign languages and translation specifically. 12 questions were posed and students were invited to answer with complete 
objectivity in order to gauge their opinion. Some questions are open and invite the students to complete a full, written answer, while others are closed and should be answered with a 'yes' or 'no' answer.

These 12 questions address various aspects related to virtual teaching in the French language. The first questions surround the availability of technology and the quality of the Internet at home and the continuity of online classes during the pandemic. The next section of questions addresses the subject of the content and the pedagogical supports received during the pandemic to ascertain whether the students considered them to have been adapted to their needs, and if they benefited from audio-visual or traditional supports. Following that, the questions address the possibility that students have had to consult these supports. Next, the questions focused on the possibility and ease of communication with peers and interaction with the teacher. And the final questions deal with the difficulties encountered the follow-up to autonomous learning, and assessing their online learning experience.

\section{Participants}

The questionnaire was published online on February 15th, 2021 and withdrawn on March the 15th of the same year. It was mainly distributed among the students of Algerian universities of languages and translation in several cities (Oran, Tlemcen, Guelma, Constantine, and Algiers among others) and it was open to all students who wished to participate, with no exceptions. The results of each question are displayed as a percentage. One hundred thirty-nine students answered and the results obtained are detailed in the next section.

\section{Research Procedures}

Once the pre-existing information on the subject had been compiled and analysed, and taking into account the observations, the interpretive approach and the inductive reasoning, a questionnaire was distributed among Algerian students to understand their difficulties closely and to be able to draw relevant conclusions.

The results obtained show the greater participation of females, who account for $81.3 \%$ for the respondents compared to $17.8 \%$ of males who have taken the time to answer this short survey. The age of the majority of the participants is between 22 and 26 years old, with a considerable percentage between 17 and 21 years old.
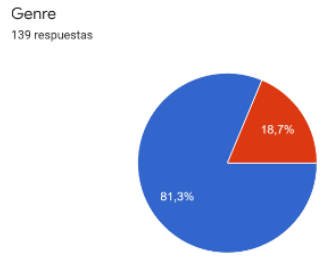

Figure 1. Gender

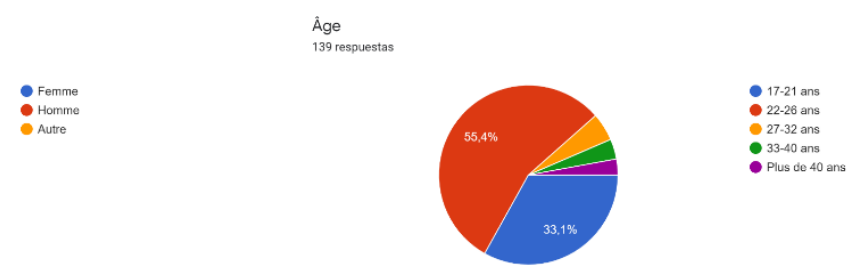

Figure 2. Age

\section{Results}

Most of the participants (73.4\%) say that they have a good enough internet connection to be able to follow the classes online, if necessary, while $76.5 \%$ indicated that they have received online classes during the pandemic period. 
1. Avez-vous internet à la maison et une connexion favorable pour suivre les cours en ligne ? 39 respuestas
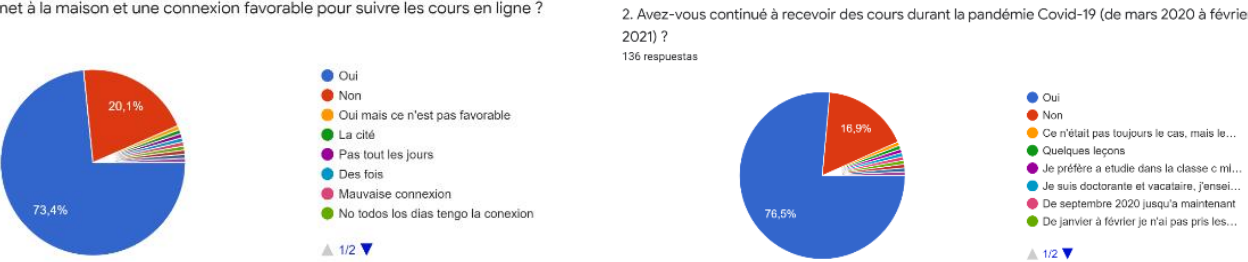

Figure 3. Favourable connection

Figure 4. Receive online classes

A lower percentage of respondents consider that they have received classes in a continuous and synchronized way (44.8\%) compared to $52.2 \%$ who have not received it in this mode. Slightly over half of the participants $(54.2 \%)$ think that the teachers have educational tools adapted to distance training.

3. Si oui, avez-vo
134 respuestas
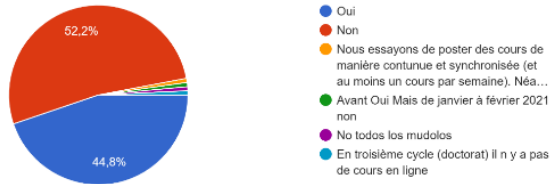

Figure 5. Continuous and synchronized classes
4. Les professeurs ont-ils proposé des supports didactiques adaptés à la formation à distance? 131 respuestas
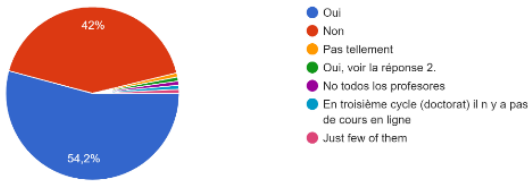

Figure 6. Didactic supports Online

Around two-thirds of the participants $(65.6 \%)$ claim that they have consulted the online platforms that have allowed them to access pedagogical spaces at the university, and $64.9 \%$ say that they have had adequate interaction with the professors.

5. Consultez-vous les plateformes en ligne qui vous permettent d'accéder aux especes pédagogiques interactifs au sein de votre Université ?
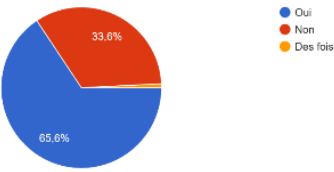

Figure 7. Interactive pedagogical spaces

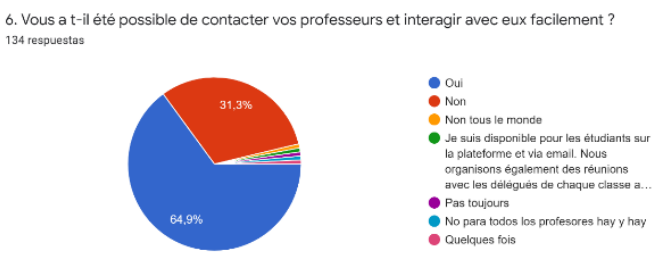

Figure 8. Interaction with teachers

Forty-five and five percent of the participants believe that the teachers have provided satisfactory audio-visual material to facilitate work at home, compared to $46.2 \%$ who do not believe it to be the case.



Figure 9. Audiovisual material 
The reasons given by the students for this failure have been the sheer lack of information, lack of direct contact with teachers, lack of technological expertise and material, lack of understanding of the material alone, lack of explanations, connection problems and poor quality of the networks. Under these circumstances, it is practically impossible to learn languages and translation since the practice and the communicative language teaching are keys to communicate outside the classroom in real life situations (Azimova, 2019).

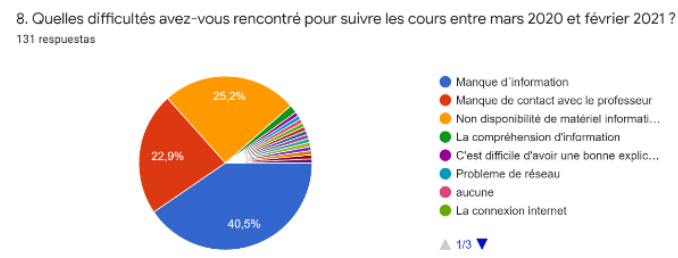

Figure 10. Difficulties of online classes

Sixty-two and two percent responded that they have studied alone, outside of class time, during the confinement period, compared to $30.9 \%$ who acknowledge not having taken the initiative to self-study. More than half of the students (55.5\%) claim they have not received any form of training to follow distance classes, compared to $39.1 \%$ of the rest of the participants who say that they have.

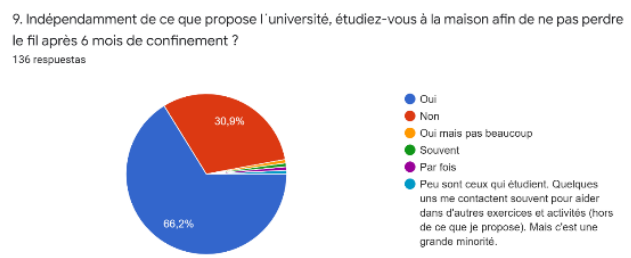

Figure 11. Universities preparation

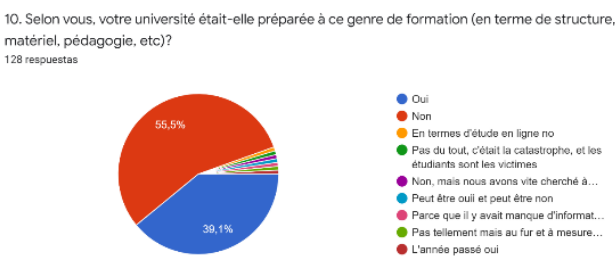

Figure 12. Virtues of online training

Half of the students consider that their online training has been beneficial for their training while $42 \%$ think otherwise, stating for the following reasons: teachers send material without explanation, lack of communication between teachers and students, lack of information, online material causes fatigue, poor connection quality, platforms are not adapted to the student's needs and lack of computer material, no external obligation to consult the material thereby discouraging the student, lack of group classes. All of this leads to demotivation, and an absence of the determined attitude that is required for learning any language.

The results obtained show that face-to-face classes are more appropriate since the teachers are not usually trained in educating at a distance nor are the students equipped for receiving it. Others consider that it is significantly more difficult to understand the material without live explanations, and they hope that teachers will be considerably more active in this regard, and that the internet connection will be greatly improved globally to help these objectives be achieved.

The most troublesome issue for students has been the difficulty in concentrating with the absence of synchronous classes, the little information received and the lack of autonomy in the 
search for information, which have resulted in online classes being a failure overall. Adding the fact that teaching methods in Algeria are traditional, a factor that should be taken into account is that students at this age are often not yet mature enough to study independently, in the sense that the student depends on the information that the teacher transmits and it may not occur to the individual to search alone. This is an aspect that slowed down the autonomy of the learner when the pandemic suddenly appeared without warning.

Reaching inclusive societies and putting online education at the discretion of each member of society is variable since circumstances differ from one society to another. One of the goals of sustainable development is to achieve equality in teaching; United Nations Sustainable Development Goals states that by 2030 all members of society have to strive to ensure inclusiveness and equity. However, the responses of different international education institutions during the COVID-19 confinement indicate that the achievement of this plan is rather unfeasible, which is the case of Algeria since the results are far from satisfactory.

\section{Discussion}

Having compiled the pre-existing information and taken into account the observations, the interpretive approach and the inductive reasoning, we proceed to develop the discussion that will allow us to point to the conclusions we have reached.

In this research, the scholars begin with the idea that the independent variable (COVID19) is a factor that enormously influenced university education in Algeria. The use of the Internet in the educational process dates back to the end of the twentieth century, though it has now become a genuine, everyday reality in its use in Algerian higher education. Most educational institutions have been forcibly reformed, by new circumstances, towards "e-learning" as an appropriate and pragmatic alternative in order to guarantee the continuation and improvement of the educational process. Hence, the use of online video and chat applications, such as Moodle, Teams, Zoom, Google Meeting, and WebXmate, among others, has seen an unrivalled usage boom with significant development.

Despite the positive aspects of e-learning, many continue to have reservations concerning its effectiveness as a total alternative to traditional methods, being forced to adapt to the new reality without, at times, being fully equipped for it. This new situation leads many to wonder about these challenges faced by e-learning in Algeria.

It is generally expected that when applying "e-Learning", both teachers and students should, theoretically, have sound knowledge and a decent grasp of Information and Communication Technologies. Furthermore, all those involved should possess a series of academic and social skills with the objective of meeting students' different requirements produced from the problems posed by distance learning. The teacher will be forced to intervene in facilitating and ensuring active participation and interaction among students, providing them with the learning material necessary for their intellectual and personal development (Germán, 2003).

This proposal appears to be dynamic due to the autonomy, motivation and interactions that facilitate and provide "e-learning". However, students can be vulnerable and sensitive to the 
lack of personalised attention and isolation during the performance of their activities. In this sense, it is necessary to emphasize that students without experience in using educational technology must be prepared for this change in order to allow autonomy in their learning process. On many occasions, the teacher may not be totally prepared for these changes and the student is exposed to learning without external help.

Orientation to students is essential not only in Algerian universities, but in all universities that have experienced this change, to allow communication in the class. Indeed, the availability of the Internet is an essential and unavoidable prerequisite in order to take advantage of the use of online models, but the involvement of teachers is more than required.

Ultimately, in order to overcome students' difficulties, distance learning must be focused on effective communication between the student and the teacher, through participation and real interaction, responding to the needs of the students to avoid a feeling of being isolated throughout the learning process. Consequently, their communicative skills in languages class will improve (Saeed \& Congman, 2013).

For these reasons, the communicative approach is considered essential in the language and translation learning process. The material posted on the university platforms alone is not enough, but more direct contact, typically via videoconference, is more than often required. Taking into account that the current generation of young people, who can be identified by their nigh on constant attachment to smartphones and suchlike, have the possibility of connecting to virtual classes whenever required to do so.

In addition to the Communicative Approach, psycholinguistics in the classroom should also be taken into account, especially given the current circumstances of a global pandemic. The complex issue of psychology in teaching is an intriguing one, particularly in language classes. Hanim Rahmat (2018) defines it as "a branch of psychology that focuses on the study and alteration of people's behaviour, including their actions, emotions and thoughts" (p. 3).

Many teachers in Algerian higher education resort to what is called "instructional design" to prepare educational material that achieves the learning objectives very efficiently. This design is generally based on the study of the educational needs of students, the establishment of objectives and the appropriate means in order to achieve them, and the tools with which to measure the effectiveness of learning and feedback. But the challenge at this point appears when the student feels overwhelmed in front of so much theoretical information without explanatory guidance. Purba (2018) comments on the necessity of applying various methods which allow students to grasp a language with ease.

Determined efforts must be made by the teacher to establish the relevant interactive means for each objective. From which it is inferred that the process of involving students in different places and holding their attention through the devices is not an easy task by any stretch of the imagination. However, it is certainly not beyond the realms of possibility as long as educational psychology is included in the methods in order to optimize learning and performance. To achieve these objectives, the educators must possess the necessary skills for vocational and professional orientation. The psychology of the language, or psycholinguistics, is 
the study of the interrelation between linguistic factors and psychological aspects. Psycholinguistics was born from the studies of the French linguist Gustave Guillaume (18831960), and it was also referred to at the beginning of the twentieth century as Guillaumism (Toussaint, 1967).

These theories should pose a motivating challenge for students. The active role of the student is aided by the help of the teacher for the optimal development of the communication process. It is recognised that communication is related to the psycholinguistic side of the student, which contributes to high quality teaching and enhances results, applying emotional intelligence (Guslyakova \& Guslyakova, 2020). It has been noted that the quantity of students in Algerian universities has risen lately; offering quality education remains equally significant. Working on the psycholinguistic side allows for more effective communication from both sides, because without the student's motivation the teacher can struggle to break the barriers to find a way of connecting with them. It must be pointed out that the situation of each person, and the effect of the pandemic on each individual, can be variable.

Another responsibility of the teacher is to use a wide variety of methods with the aim of meeting the different needs of the students. Focusing on speaking from the teacher's side might be convenient, straightforward and sometimes necessary, but it can be uninteresting and lacking in stimulation without visual and dynamic activities. Here, the teacher has to adopt the appropriate programs and applications to propose a "variety" of appropriate live educational materials to capture the student's attention. To achieve this, the importance of technology has to be considered, as explained by Hadjeris (2020): "The challenges of the $21^{\text {st }}$ century, that is, "digital skills". For the improvement of the quality in online teaching in Algerian higher education institutions, teachers and education programs should consider the importance of technological skills" (p. 167).

Accompanying the students and the technology applied to teaching, with emotional mechanisms is key to achieving the pedagogical objectives in the language class. The teacher is the one who must provide creative solutions that allow the student to get involved in a dynamic and communicative learning process. The following factors must be taken into account:

- The age of the students and the need to accompany them in the learning process, adopting emotional mechanisms that can attract them to interact in class.

- Being responsible as teachers for detecting technological failures and offer possible solutions to students.

- Getting involved as teachers to accompany students to form productive and conscientious citizens and not limit ourselves to giving master classes.

- Not waiting for political changes and offer support to students to form competent individuals.

One of the goals set by the United Nations is to offer a free education to all students without exception, a benefit which currently exists in all public Algerian universities. Students have the advantage of equitable access to higher education, but it is imperative to offer them high quality courses with effective results. In this case, distance studies in language and translation faculties must achieve this objective with the effective participation of teachers as the protagonists of the content, encouraging students to attend communicative classes, based on 
effective communication, such as key methodology that allows participation, exchange of ideas, and discussion in class. This offers a fantastic opportunity for students who are developing their professional profiles during their academic career. Many learners are lost at this age and lack direction and the teacher must be the guide to achieve not only academic objectives but also promote educational competencies; a combination of knowledge, skills and attitudes that are put into action for an adequate performance. This leads to the development of many other competencies in the students' career, such as tolerance, debate, sharing ideas and, consequently, helping to create peaceful and productive societies.

It is not merely about teaching to give marks and categorise students with a "pass" or a "fail", but training the student to grow on a personal level, using the technology that is the very near future of all societies, if not the current reality. And for this, the active participation of teachers is required as the main protagonists, particularly during times of political turmoil, which is the case in Algeria. It also calls for the government's involvement in massive investment in education, which is the only way to near enough guarantee a prosperous future for Algeria. It is not impossible, history shows that. After gaining independence in 1962, when the percentage of educated people was very low, Algeria showed more of a willingness to invest in education; it should be even more straightforward nowadays given that there is a much higher percentage of trained teachers and professionals. Also, the promotion of educational policies and private investments in this sector are requested, which could give a boost, especially when basic and achievable needs, such as a reliable Internet connection in all homes, are not met. Instead of investing in commerce as is often the case in Algeria, increasing the education budget can bring many more qualified professionals to society.

During the acquisition of the language, there is a significant role of emotion, and this is encouraged by the teacher through appropriate methods and techniques for each context and culture; many methods are intuitive and flexible - therefore, they can be adapted to each group and its dynamics. There are several competitive games, role-playing activities, exercises with visual illustrations, conversations, etc., that can make the class dynamic and connect the student without the need for material investments, but with dedication of time and empathy towards our students. In this way, the student feels involved in the class, appreciated because they can give their opinions and can develop their emotional and cognitive intelligence, and thus dialogue is created in class, and consequently there is a challenge for the student to learn to create dialogue outside of it. In this way, feelings of belonging to society are produced and discrimination is reduced. Technology is a tool to bring ideas and people closer together. We can even make exchanges between online universities with simple platforms. A bridge between cultures, which can encourage discussion, positivity and progression between all involved, reflections can be fruitful and complementary, collective participation and respect for diversity. Methodologies change and we cannot stagnate when technology offers a range of simple, low-cost platforms adapted to the Algerian context and pedagogical content.

Thus, the standardisation of this mode of teaching at the national level could be done with prerequisites for teacher training, administrative staff and students in the use and appropriation of information and communication technology and digital platforms for teaching and learning. It is increasingly common in high profile speeches to point out the need to rethink education by giving priority among the new contents to the preparation of students to understand reality, 
coexist and live together and act in times of crisis and uncertainty, to make decisions at the individual and family levels and to promote collective solutions to urgent challenges that contribute to the structural transformation of the world.

\section{Limitations}

We must express the limitation of this investigation due to time constraints. We have not been able to obtain the compilation of the emotional mechanisms introduced by the Algerian teachers, which could offer a path of investigation in order to offer solutions and quality education in the short term.

Even with these limitations, we are well-positioned to answer the question that we asked at the beginning. The Algerian students experiences many difficulties with the new learning modality and developing the communicative and emotional competencies to motivate them is essential, so that they can trust themselves and can reflect and make the relevant decisions clearly and confidently, and therefore, it possible to form citizens committed in society.

\section{Conclusion}

The world has been immersed in an unprecedented global crisis. The virulence of the Coronavirus (COVID-19) has not only posed a public health danger, but it has also hugely impacted all sectors. The educational community has shown resilience and has laid the foundations for recovery. In Algeria, despite the inadequate preparation by the vast majority of universities, MESRS (Ministry of Higher Education) was proactive in trying to propose alternatives and solutions, however basic, to be able to carry out the academic year 2019/2020 and begin the following university year. The main objective of this study is to assess the state of art of e-learning through the experience of the students and their difficulties to understand the goals of the Algerian universities. Several reasons have been put forward in the analysis of the answers to the developed questionnaire, in particular the lack of fluid communication between the student and the teacher, the unavailability of computer equipment - which is added to by the major problem of the Internet connection - and the lack of an interactive database for the student, which made monitoring and evaluating the student almost impossible. Furthermore, there can be an absence of certain teaching methods, such as the communicative and psycholinguistic method, during distance learning.

One of the sustainable development goals is to offer quality education, implementing innovative and context-appropriate solutions to provide distance education, taking advantage of high-tech approaches (Sustainable Development Goal 4). It is an attainable objective in Algeria, given that the platforms have already been in existence for a couple of years. It is true, though, that the students and the teachers were not prepared for such a situation. The lack of coordination and involvement among members of the universities was one of the major contributors to the failure to accomplish this goal in Algeria. In summary, the current COVID-19 pandemic poses major challenges to the educational systems of Algeria, which will need to be addressed in a coordinated manner. These challenges and lessons offer us today the opportunity to rethink the purpose of education and its role in the intellectual and critical growth of our students, so that no one is left behind. In other words, while countries consider how best to address uncertainties and reopen their educational institutions in safety, this crisis offers an unprecedented opportunity to increase the resilience of national education systems and transform them into equitable and 
inclusive systems that contribute to the fulfilment of the collective commitment of a country like Algeria.

\section{About the authors:}

Dr. Nassima Kerras received her $\mathrm{PhD}$ in translation and interpreting from the University of Granada in 2012. She is an associate professor of Languages and Culture at University of Pompeu Fabra, ESADE and Blanquerna, and professor of Sociolinguistics in Autonomous University of Barcelona (Spain). Member of the Research Group HUM-835 "Translation, Knowledge and Culture". Her dissertation focused on pragmatic, sociocultural, and contextual aspects of multilingual multimedia texts. https://orcid.org/0000-0002-9700-8257

Dr Salah is an assistant professor and research associate in the Department of Cultures and Foreign Languages of the Abou Bekr Belkaid University in Tlemcen, since November 2013. He was a visiting researcher at the University of Castilla la Mancha in Toledo, from October 2016 to April 2018. He is also an associate researcher at the National Centre for Prehistoric, Anthropological and Historical Research (CNRPAH) in Algiers. His lines of research focus on education strategies, economic and technical Spanish language, foreign languages teaching, Spanish with specific purposes. https://orcid.org/0000-0001-9128-0850

\section{References}

Abdelouafi, H. (2020). E-Learning Experience at Algerian Universities during Covid-19: University of Draia Adrar as a Model. Innovative Pedagogies in the Pandemic Era and Beyond, 6(2), 1-13.

Alla, A. (2021). Requirements for the Development of the Higher Education System and Awareness of the Implications of the Covid-19 Outbreak. Predictions and Future Prospects, 16(1), 285-309. Available at https://www.asjp.cerist.dz/en/article/144329

Arabeche Z., \& Soudani A. (2021). Perception of E-learning during the Health Crisis of COVID19: Case of Algerian University Teachers. Journal of Information Technology Management, 13(2), 154-172. DOI: 10.22059/jitm.2021.80360

Azimova, Sh. (2019). The communicative approach in English language teaching. Bulletin of Science and Practice, 5(4), 471-475.

Balboni, P. E. (2017). Translation in Language Learning a "what for" approach. Entrelinguas, 3(2), 276-299. DOI: 10.29051/rel.v3.n2.2017.9546

Bashitialshaeaer, R., Alhendawi, M., \& Lassoued, Z. (2021). Obstacle Comparisons to Achieving Distance Learning and Applying Electronic Exams during Covid-19 Pandemic. Symettry, 13, 1-16. DOI: https://doi.org/10.3390/sym13010099.

Benkhider, N., \& Kherbachi, S. (2020). The influence of remote learning on student's learning habits during Covid-19. Les cahiers du Cread, 36(3), 425-448.

Blizak, D., Blizak, S., Bouchenak, O., \& Yahiaoui, K. (2020). Students' Perceptions Regarding the Abrupt Transition to Online Learning During the COVID-19 Pandemic: Case of Faculty of Chemistry and Hydrocarbons at the University of Boumerdes-Algeria. Journal of Chemical Education, 97 (9), 2466-2471 DOI: 10.1021/acs.jchemed.0c00668 https://pubs.acs.org/doi/abs/10.1021/acs.jchemed.0c00668 
Chelghoum A., \& Chelghoum H. (2020). The Covid-19 Pandemic and Education: Big Changes Ahead For Teaching in Algeria. ALTRALANG, 2(2), 118-132. https://www.asjp.cerist.dz/en/article/139887

Cherry, K. (2016). History and Key Concepts of Behavoiral Psychology. Available at: <https://www.verywellmind.com/behavioral-psychology-4157183>

Deli Girik Allo, M. (2020). Is the online learning good in the midst of Covid-19 Pandemic? The case of EFL learners. Journal Sinestesia, 10(1), 1-10.

Ellis, R., Skehan, P., Li, Sh., \& Lambert, C. (2019). Task-based language teaching: theory and practice. Cambridge: University Press.

German, R. (2003). Educación virtual y E-Learning [Virtual Education and E-Learning]. Madrid: Fundación Auna.

Guemide, B., \& Maouche, S. (2020). Assessment of Distance Learning in the Algerian Universities during the COVID-19. International Journal of Distance Education and ELearning, 6(1). Available at http://irigs.iiu.edu.pk:64447/ojs/index.php/IJDEEL/article/view/1420

Guemide, B., \& Maouche, S. (2021). Assessment of online learning in Algerian universities during COVID-19. Journal for Humanitarian Science, 490-515. Available at https://jh.alkutcollege.edu.iq/article_10553_302.html

Guemide, B., \& Maouche, S. (2020). Assessment of Online Learning in Algerian Universities during Covid-19. Kut University College Journal of Humanitarian Science, 6(1), 490515.

Guessar, S. (2020). Algerian university during the Corona Virus pandemic: Covid-19. European Journal of Education, 3(2), 73-81.

Guofang, L. (2020). Principals of developing learner agency in language learning in a new Eduscape with Covid-19. Language Learning, 5, 33-43.

Guslyakova, N. \& Guslyakova, A. (2020). Emotional Intelligence as a Driving Force in the Study of Foreign Languages in Higher Education. ARPHA Proceedings, 3, 781-792. DOI: http://doi.org/10.3897/ap.2.e0781

Hadjeris, F. (2020). Revisiting Sustainable Development Goal 4 in the context of Covid-19 pandemic: a case study of online teaching in Algerian higher education institutions. Wiley Periodicals LLC, 3, 160-168.

Halliday, M. A. K. (1975). Learning How to Mean: Explorations in the Development of Language. London: Edward Arnold.

Hanim Rahmat, N. (2018). Educational Psychology: A tool for language research. People: International Journal of Social Sciences, 4(2), 655-668.

Hymes, D. H. (1972). On Communicative Competence, In J. B. Pride, \& J. Holmes, (eds.): Sociolinguistics (pp. 269-293). Penguin Books Ltd.

IESALC. (2020). Covid-19 and higher education: today and tomorrow. Available at https://n9.cl/k731y

Khelfaoui, H. (2021). L'enseignement professionnel en Algérie : contraintes institutionnelles et réponses sociales [Professional education in Algeria : Institutional constraints and social responses]. Sociologie et sociétés, 40(1), 143-170. DOI: https://doi.org/10.7202/019476ar

Lassassi, M., Lounici, N., Sami, L., Tidjani, Che., \& Benguerna, M. (2020). Université et enseignants face au Covid-19 : l'épreuve de l'enseignement à distance en Algérie [University and teachers facing Covid-19: the ordeal of distance education in Algeria]. Les Cahiers du Cread, 36(3), 397-424. 
Lassoued, Z., Alhendawi, M., \& Bashitialshaaer, R. (2020). An exploratory study of the obstacles for achieving quality in distance learning during the Covid-19 pandemic. Education Sciences, 10, 1-3.

Makhlouf, A. (2020). L'usage de l'enseignement à distance en Algérie à l'heure de la crise sanitaire Covid-19 : entre solutions provisoires et un nouveau mode d'apprentissage en ligne qui s'impose dans le futur. Cas de l'Université de Béjaia [The use of distance education in Algeria at a time of the Covid-19 health crisis: between interim solutions and a new online learning mode that is needed in the future. Case of the University of Béjaia]. Revue de Recherches Francophones en Sciences de l'information et de la Communication, 9(19), 1-20.

Priyo, A., Arief, E., \& Nugroho, A. (2020). EFL Classes Must Go Online! Teaching Activities and Challenges during COVID-19 Pandemic. Indonesia Register Journal, 13(1), 49-76.

Purba, N. (2018). The role of psycholinguistics in language learning and teaching. Tell Journal, 6(1), 47-54.

Rapanta, Ch., Botturi, L., Goodyear, P., Guàrdia, L., \& Koole, M. (2020). Online University Teaching During and After the Covid-19 Crisis: Refocusing Teacher Presence and Learning Activity. Postdigital Science and Education, 2, 923-945.

Reimers, F., \& Schleicher, A. (2020). A framework to guide an education response to the Covid19 pandemic of 2020. OECD. Available at https://n9.cl/0sqy2

Saeed, A., \& Congman, R. (2013). Applying communicative approach in teaching English as a foreign language: a case study of Pakistan. Porta Linguarum, 20, 187-203.

Skinner, B. F. (1957). Verbal Behaviour. New York: Appleton Century Crofts.

TNTP. (2020). Supporting multilingual learners (MLLs)/ English language (ELLs) during the covid-19 Shutdown. Available at https://n9.cl/cz5nq

Toussaint, M. (1967). Gustave Guillaume et l'actualité linguistique [Gustave Guillaume and linguistic news]. Langages, 7, 93-100.

Zermane, H., \& Aitouche, S. (2020). Digital Learning with Covid-19 in Algeria. International Journal of 3D printing technologies and digital industry, 4(2), 161-170. 